Surg Endosc (2004) 18: 1829-1831

DOI: $10.1007 / \mathrm{s} 00464-004-0089-y$

(C) Springer Science+Business Media, Inc. 2004

\section{The Association of Endoscopic Surgeons of Great Britain and Ireland}

The AESGBI office has moved from the Oaks Hospital Colchester. All correspondence should be addressed to:

Association of Endoscopic Surgeons of Great Britain and Ireland The Royal College of Surgeons

35/43 Lincoln's Inn Fields

London WC2A 3PN, UK

Tel: $0044(0) 1719730305$

Fax: 0044 (0)171 4309235

E-mail: jrabone@asgbi.org.uk

\section{Courses at Colchester General Hospital}

Advanced laparoscopic courses take place in February and October each year. They provide delegates with individual tuition including lectures, practical sessions and live operative demonstrations. The courses cover advanced techniques for gallstone disease and the operative sessions include laparoscopic hernia repair, both trans- and extra-peritoneal, fundoplication for hiatus hernia and colon resection or rectopexy.

\section{Course Content:}

Advanced techniques in laparoscopic cholecystectomy

Detection of common bile duct stones/operative cholangiography Laparoscopic exploration of the common bile duct

Simulator sessions including knot tying, suturing, cholangiography Case demonstrations as described above,

The course fee of $£ 495$ includes two nights hotel accommodation including breakfast, course dinner, lunch and refreshments, course manual and videotape, all course materials and VAT.

For further information contact the course director:

Prof. Roger Motson

Colchester General Hospital

Turner Road

Colchester, Essex, CO4 5JL, UK

Tel: 00441206742448

Fax: 00441206742030

E-mail: sarah.wilby@essexrivers.nhs.uk

\section{Essentials of Laparoscopic Surgery \\ Surgical Skills Unit \\ University of Dundee \\ Scotland, UK}

Under the direction of Sir A. Cuschieri the Surgical Skills Unit is offering a three-day practical course designed for surgeons who wish to undertake the procedures such as laparoscopic cholecystectomy. This intensely practical program develops the necessary operating skills, emphasizes safe practice, and highlights the common pitfalls and difficulties encountered when starting out. Each workshop has a maximum of 18 participants who will learn both camera and instrument-manipulation skills in a purpose- built skills laboratory. During the course there is a live demonstration of a laparoscopic cholecystectomy. The unit has a large library of operative videos

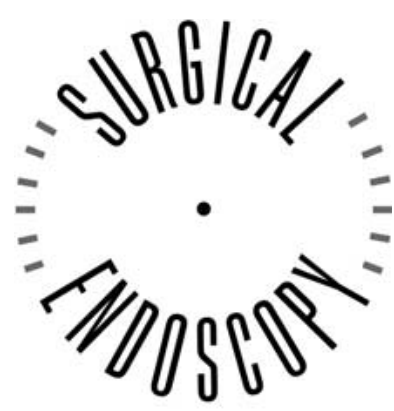

and Other Interventional Techniques

edited by Sir Cuschieri, and the latest books on endoscopic surgery are on display in our Resource area. Course fee including lunch and course materials is $\$ 860$.

For further details and a brochure please contact:

Julie Struthers, Unit Co-ordinator

Surgical Skills Unit

Ninewells Hospital and Medical School

Dundee DDI 9SY, Scotland, UK

Tel: +44382645857

Fax: +44382646042

\section{Minimal Access Therapy Training Courses}

Surgical Skills Unit

University of Dundee, Scotland, UK

Unit Director: Sir Alfred Cuschieri

The Surgical Skills unit offers practical courses in minimal access therapies. Each program is organized to have maximum "hands on" practice sessions in the purpose-built laboratory. Subject experts are available for tuition and personal feedback. Live operative demonstrations on specific procedures form part of each course; these are backed up by video illustrations. Each course has a workbook with essential information, clear explanations, and guidelines. Informal discussion sessions with subject experts form part of each program. The courses are run regularly throughout the year.

Essentials of Laparoscopic Surgery, a 3-day course covering the essential skills and safety procedures for basic laparoscopic operations.

Foundations of Laparoscopy Surgery, a 5-day course presenting an extensive and detailed introduction to laparoseopic surgery.

Practical Training in Pediatric Endoscopic Surgery, a 5-day course for surgeons who wish to perform or refine endoscopic surgical techniques in children.

The Advanced Endoscopic Surgical Courses of the Royal College of Surgeons of Edinburgh are held in the Surgical Skills Unit.

These are: Advanced Endoscopic Skills Course, a 5-day endoscopic skills training in advanced surgical tasks common to all specialities, e.g., intracorporeal and extracorporeal knot tying, internal continuous and interrupted suturing, anastomosis of organs, stapling, use of sophisticated equipment such as ultrasound and harmonic dissections and Specialist Procedure-related courses, which are 2-3 days long and concentrate on specific clinical situations particularly relevant to a speciality and focused on specific endoscopic operation(s).

Ductal Calculi: The Laparoscopic Approach

Practical Aspects of Laparoscopic Fundoplication

Laparoscopic Colorectal Course

Thoracoscopic Sympathectomy

Other specialist courses held in the unit include courses in anaesthetic techniques, arthroscopy, colonoscopy, endoscopy, gynecology, and otolaryngology.

For further information you can visit our web site or contact:

Julie Struthers, Unit Co-ordinator

Surgical Skills Unit

Ninewells Hospital and Medical School

Dundee DD1 9SY, Scotland, UK

Tel: +44 1382645857

Fax: + 441382646042

E-mail: j.e.a.struthers@dundee.ac.uk

Web page: http://www.dundee.ac.uk/surgicalskills/ 


\section{Courses at the Royal Adelaide Centre for Endoscopic Surgery}

Basic and Advanced Laparoscopic Skills Courses are conducted by the Royal Adelaide Centre for Endoscopic Surgery on a regular basis. The courses are limited to six places to maximize skill development and tuition. Basic courses are conducted over two days for trainees and surgeons seeking an introduction to laparoscopic cholecystectomy. Animal viscera in simulators is used to develop practical skills. Advanced courses are conducted over four days for surgeons already experienced in laparoscopic cholecystectomy who wish to undertake more advanced procedures. A wide range of procedures are included, although practical sessions can be tailored to one or two procedures at the participants request. Practical skills are developed using training simulators and anaesthetised pigs.

Course fees: \$A300 (\$US225) for the basic course and \$A1,600 (\$US1,200) for the advanced course.

For further details and a brochure please contact:

Dr. D. I. Watson or Professor G. G. Jamieson

The Royal Adelaide Centre for Endoscopic Surgery

Department of Surgery

Royal Adelaide Hospital

Adelaide, SA 5000, Australia

Tel: +6182245516

Fax: +6182323471

\section{Advanced Laparoscopic Suturing and Surgical Skills Courses}

MOET Institute

San Francisco, CA, USA

Courses are offered year-round by individual arrangement. The MOET Institute is accredited by the Accreditation Council for Continuing Medical Education (ACCME) to provide continuing medical education for physicians and designates these CME activities for 20-40 credit hours in Category I of the Physician's Recognition Award of the American Medical Association. These programs are also endorsed by the Society of Gastrointestinal Endoscopic Surgeons (SAGES).

For further information please contact:

Wanda Toy, Program Administrator

Microsurgery \& Operative Endoscopy Training (MOET) Institute

153 States Street

San Francisco, CA 94114, USA

Tel: (415) 626-3400

Fax: (415) 626-3444

\section{Fellowships in Minimally Invasive Thoracic and General Surgery}

University of Pittsburgh Medical Center

Pittsburgh, PA, USA

One-year fellowships in advanced Minimally Invasive Surgery in General and Thoracic Surgery are being offered at the University of Pittsburgh Medical Center. Requirements include completion of residence training programs in General or Thoracic Surgery. The fellowships will involve extensive clinical exposure as well as clinical and basic science research. These positions include a very competitive salary and travel allowance. Interested candidates are invited to send a letter of inquiry with a curriculum vitae to:

Philip R. Schauer, M.D.

Assistant Professor of Surgery and Co-Director for General Surgery James Luketich, M.D.

Assistant Professor of Surgery and Co-Director for Thoracic Surgery The University of Pittsburgh Medical Center

C-800 Presbyterian University Hospital

200 Lothrop Street

Pittsburgh, PA 15213-3221, USA

\section{Geisinger Medical Center Fellowship in Minimally Invasive Surgery}

A one-year fellowship in advanced minimally invasive general and thoracic surgery is available at Geisinger Medical Center. The fellowship will involve extensive clinical exposure to UGI, bariatric and thoracic minimally invasive surgery with emphasis on esophageal surgery for benign and malignant disease. Fellows will also participate in clinical outcomes research. Requirements include completion of residency training in general surgery or thoracic surgery. Competitive salary and benefits package including travel allowances are available. Interested candidates are invited to send a letter of inquiry and curriculum vitae to:

Anthony T. Petrick, MD

Director, Minimally Invasive Surgery

Geisinger Medical Center

100 North Academy Avenue

Danville, PA 17821-2111, USA

atpetrick@geisinger.edu

\section{Clinical Fellowship in Laparoscopic Surgery \\ Mount Sinai School of Medicine, New York, NY, USA Program Director: Daniel Herron, M.D.}

The Mount Sinai Clinical Fellowship in Laparoscopy is a 1-year position offered to two individuals each academic year. Fellows rotate through several clinical rotations, each one emphasizing a different aspect of minimally invasive surgery. During the bariatric rotation, the fellow will gain a broad exposure to laparoscopic gastric bypass, laparoscopic biliopancreatic diversion with duodenal switch and the laparoscopic adjustable gastric band. Additionally, the fellow will learn 2-stage approaches to supermorbid obesity and laparoscopic revisional surgery. In the GI rotation, the fellow joins one of the busiest laparoscopic foregut surgery groups in the East Coast, scrubbing on a large number of fundoplications, paraesophageal hernias, Heller myotomies, and gastroesophageal resections. This rotation also provides a strong experience in laparoscopic partial and subtotal colectomy as well as laparoscopic surgery for Crohn's disease. Solid organ surgery comprises another highlight of the fellowship, with two or more laparoscopic donor nephrectomies performed each week. Fellows will participate in several clinical research projects during the year and will be expected to present their results at a national meeting. Both the Fellowship Director and the Laparoscopic Division Chief have served on the Board of Governors of SAGES and strongly encourage Fellow participation in SAGES courses and committees. Fellows are provided with access to professional-quality video recording and editing equipment, and are formally trained in the use of this equipment to prepare academic video presentations. Numerous opportunities to write review articles and book chapters are available. Fellows will present in both General Surgery and Laparoscopic Surgery Grand Rounds. Fellows play an active role in the education of residents and medical students.

To apply, please visit www.misfellowshipcouncil.org.

\section{Advanced Clinical Minimally Invasive Fellowship}

Harvard Medical School

Both Israel Deaconess Medical Center

Boston, Massachusetts, USA

Advanced Clinical Minimally Invasive Fellowship with emphasis on Bariatric Surgery, (One-year position begins July 2003). Interested candidates are invited to send curriculum vitae to:

Daniel B. Jones, M.D., F.A.C.S.

Chief, Section of Minimally Invasive Surgery

Harvard Medical School

Beth Israel Deaconess Medical Center

Shapiro TCC 140

330 Brookline Avenue

Boston, MA 02215, USA

\section{Minimally Invasive Surgery Research Fellowships}

Mount Sinai Minimally Invasive Surgery Center Mount Sinai School of Medicine, New York, NY, USA 
Center Director: Barry Salky, M.D.

Research fellowships are sponsored by the Mount Sinai MISC for qualified individuals who are interested in an in-residence experience working under the guidance of MISC faculty. The MISC research fellowship program is extremely competitive, and the Center receives numerous applications each year for only a few positions. Applications for research fellowships are accepted up to six months in advance of the expected start date.

For more information on this program (and all Mount Sinai Minimally Invasive Surgery Center activities), please visit www.mssm.edu/ misc.

To apply for a research fellowship, contact:

Benjamin Green

Manager

Mount Sinai Minimally Invasive Surgery Center

One Gustave L. Levy Place

Box 1259

New York, NY 10029, USA

benjamin.green@mountsinai.org

\section{Carolinas Laparoscopic and Advanced Surgery Program (CLASP)}

A Division of Carolinas Medical Center in Charlotte, NC, USA

Program Directors: B. Todd Heniford, Frederick L. Greene

\section{Courses offered in the year 2004}

\section{Laparoscopic Ventral and Incisional Herniorrhaphy Workshop}

The purpose of this course is to teach laparoscopic techniques for ventral hernia repair, discuss the different prosthetic materials, their application, and associated healing process, and describing the techniques for minimally invasive access in the multiply operated abdomen. Location: Carolinas Medical Center; One day course consisting of $1 / 2$-day didactic and 1/2-day hands-on lab.

Course Fee: $\$ 250.00$

Faculty: B. Todd Heniford, M.D., (Course Director); Kent Kercher, M.D., Brent Matthews, M.D., and/or Bruce Ramshaw, M.D., Guy Voeller, M.D., or Adrian Park, M.D. as guest faculty.

Course dates remaining for the year 2004: December 10, 2004.

\section{CLASP Program Directors:}

B. Todd Heniford, M.D.

Chief of Minimal Access Surgery

Codirector-Carolinas Laparoscopic and Advanced Surgery Program Carolinas Medical Center

Frederick L. Greene, M.D.

Chairman, Department of General Surgery

Codirector-Carolinas Laparoscopic and Advanced Surgery Program Carolinas Medical Center

\section{Nineteenth International Workshop on Therapeutic Endoscopy}

Hong Kong

November 30 - December 2, 2004

This function is jointly organized by The Chinese University of Hong Kong and the Hong Kong Society of Digestive Endoscopy. The 19th Workshop will see some changes. This year we will strengthen the faculty by bringing in a record number of international experts from five continents. The workshop will feature not only our usual format of "how-I-do-it" lectures and live procedures to be critiqued and commented by international experts and the audience. We will introduce video sessions where experts will discuss selected case scenarios and various endoscopic techniques. There will be a more structured program with sessions dedicated to chromo-endoscopy, newer imaging modalities, and mucosectomy in the context of early upper gastrointestinal malignancies.

Correspondence to:

Dr. James Lau

Endoscopy Centre

The Chinese University of Hong Kong

Prince of Wales Hospital, Shatin, NT, Hong Kong

Tel: (852) 2632-2233; Fax: (852) 2635-0075

E-mail: info@hksde.org

\section{Endosurgery '05}

An International Congress on Minimal Access Surgery February 24-26, 2005

Theme: "Mechanism of mishaps and risk reduction strategies". Organized by: Department of Minimal Access Surgery, Sir Ganga Ram Hospital, New Delhi, India, under the auspices of Indian Association of Gastro-intestinal Endosurgeons (IAGES).

Interested surgeons may send their online request through e-mail or write to:

Dr. Pradeep Chowbey

Organizing Chairman

AYUSHMAN

Double Storey Market

R-Block, New Rajinder Nagar, New Delhi-110 060, India

Tel.: +91-11-25821768/25748085/28741188/28742929

Fax: +91-11-26519935/25748085

e-mail: chowbey1@.vsnl.com / pk_chowbey@yahoo.com

website: www.sgrh.com / www.MĀSone.org

\section{7th Asia Pacific Congress of Endoscopic Surgery (ELSA 2004)}

Hong Kong

August 17-19, 2005

The Congress is jointly organized by the Endoscopic \& Laparoscopic Surgeons of Asia, Hong Kong Society of Minimal Access Surgery, and Department of Surgery of The Chinese University of Hong Kong.

Please visit www.elsa2005.org or contact the Congress Secretariat via email at info@elsa2005.org for information regarding the Congress. 